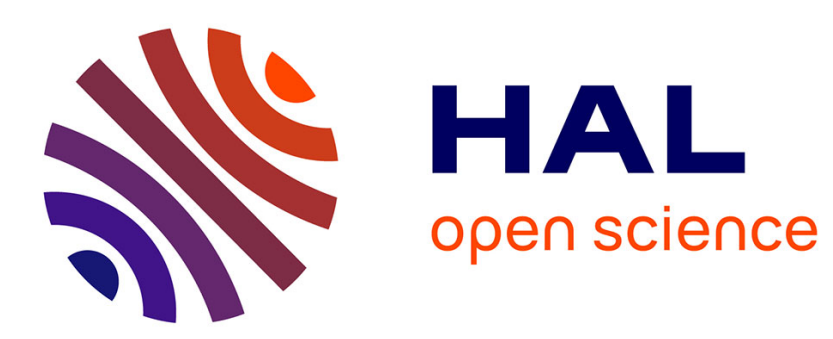

\title{
Outstanding performance of activated graphene based supercapacitors in ionic liquid electrolyte from -50 to $80^{\circ} \mathrm{C}$
}

Wan-Yu Tsai, Rongying Lin, Shanthi Murali, Li Li Zhang, John K. Mcdonough, Rodney S. Ruoff, Pierre-Louis Taberna, Yury Gogotsi, Patrice Simon

\section{To cite this version:}

Wan-Yu Tsai, Rongying Lin, Shanthi Murali, Li Li Zhang, John K. Mcdonough, et al.. Outstanding performance of activated graphene based supercapacitors in ionic liquid electrolyte from -50 to $80^{\circ} \mathrm{C}$. Nano Energy, 2013, vol. 2 ( $\mathrm{n}^{\circ} 3$ ), pp. 403-411. 10.1016/j.nanoen.2012.11.006 . hal-01154261

\author{
HAL Id: hal-01154261 \\ https://hal.science/hal-01154261
}

Submitted on 21 May 2015

HAL is a multi-disciplinary open access archive for the deposit and dissemination of scientific research documents, whether they are published or not. The documents may come from teaching and research institutions in France or abroad, or from public or private research centers.
L'archive ouverte pluridisciplinaire $\mathbf{H A L}$, est destinée au dépôt et à la diffusion de documents scientifiques de niveau recherche, publiés ou non, émanant des établissements d'enseignement et de recherche français ou étrangers, des laboratoires publics ou privés. 


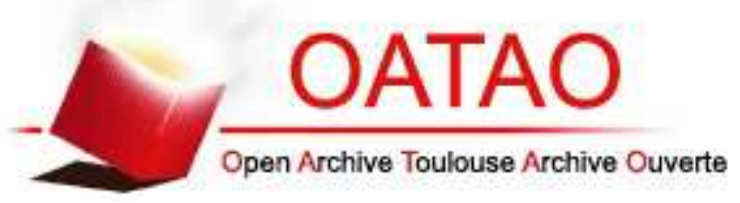

\section{Open Archive TOULOUSE Archive Ouverte (OATAO)}

OATAO is an open access repository that collects the work of Toulouse researchers and makes it freely available over the web where possible.

This is an author-deposited version published in : http://oatao.univ-toulouse.fr/ Eprints ID : 13894

To link to this article : DOI:10.1016/j.nanoen.2012.11.006

URL : http://dx.doi.org/10.1016/j.nanoen.2012.11.006

\section{To cite this version :}

Tsai, Wan-Yu and Lin, Rongying and Murali, Shanthi and Zhang, Li Li and McDonough, John K. and Ruoff, Rodney S. and Taberna, Pierre-Louis and Gogotsi, Yury and Simon, Patrice Outstanding performance of activated graphene based supercapacitors in ionic liquid electrolyte from -50 to $80^{\circ} \mathrm{C}$. (2013) Nano Energy, vol. $2\left(\mathrm{n}^{\circ}\right.$ 3). pp. 403-411. ISSN 2211-2855

Any correspondance concerning this service should be sent to the repository administrator: staff-oatao@ listes-diff.inp-toulouse.fr 


\title{
Outstanding performance of activated graphene based supercapacitors in ionic liquid electrolyte from -50 to $80{ }^{\circ} \mathrm{C}$
}

\author{
Wan-Yu Tsai ${ }^{a}$, Rongying Lin ${ }^{a}$, Shanthi Muralic, Li Li Zhang ${ }^{c}$, \\ John K. McDonough ${ }^{d}$, Rodney S. Ruoff ${ }^{c}$, Pierre-Louis Taberna ${ }^{a}$, \\ Yury Gogotsi ${ }^{\mathrm{d}, *}$, Patrice Simon ${ }^{\mathrm{a}, \mathrm{b}, * * *}$
}

\begin{abstract}
aUniversité Paul Sabatier, CIRIMAT UMR CNRS 5085, 118 route de Narbonne, 31062 Toulouse, France
${ }^{\mathrm{b}}$ Réseau sur le Stockage Electrochimique de l'Energie (RS2E), FR CNRS 3459, France

'Department of Mechanical Engineering and the Materials Science and Engineering Program, The University of Texas at Austin, One University Station C2200, Austin, TX 78712, United States

${ }^{\mathrm{d}}$ Department of Materials Science and Engineering \& A.J. Drexel Nanotechnology Institute, Drexel University, 3141 Chestnut St., Philadelphia, PA 19104, United States
\end{abstract}

\author{
KEYWORDS \\ Electrochemical \\ capacitors; \\ Activated graphene; \\ Ionic liquid mixture; \\ Wide temperature \\ range
}

\begin{abstract}
High specific surface area (SSA $\sim 2000 \mathrm{~m}^{2} / \mathrm{g}$ ) porous $\mathrm{KOH}$-activated microwave exfoliated graphite oxide ('a-MEGO') electrodes have been tested in a eutectic mixture of ionic liquids ( $1: 1$ by weight or molar ratio $\mathrm{N}$-methyl- $\mathrm{N}$-propylpiperidinium bis(fluorosulfonyl)imide $\left(\mathrm{PIP}_{13}-\mathrm{FSI}\right.$ ) and $\mathrm{N}$-butyl- $\mathrm{N}$ methylpyrrolidinium bis(fluorosulfonyl)imide $\left(\mathrm{PYR}_{14}-\mathrm{FSI}\right)$ ) as electrolyte for supercapacitor applications. By optimizing the carbon/electrolyte system, outstanding capacitive performance has been achieved with high capacitance (up to $180 \mathrm{~F} / \mathrm{g}$ ) and wide electrochemical window (up to $3.5 \mathrm{~V}$ ) over a wide temperature range from $-50{ }^{\circ} \mathrm{C}$ to $80^{\circ} \mathrm{C}$. This is the first demonstration of a carbon-ionic liquid system capable of delivering capacitance in excess of $100 \mathrm{~F} / \mathrm{g}$ below room temperature. The excellent electrochemical response of the proposed couple shows that optimization of the carbon/electrolyte interface is of great importance for improving capacitive energy storage.
\end{abstract}

\section{Introduction}

Electrochemical double layer capacitors (EDLCs), also known as supercapacitors, store electrical charges between electrode materials and electrolyte ions by electrostatic 
attractions. Supercapacitors had their debut mainly in CMOS memory back-up and are now widely used in power electronics for peak power shaving and back-up supplies (as support for power disruption). Today, one of the most promising applications is their use in transportation (in hybrid-electric vehicles (HEVs) in particular) for harvesting braking energy and for faster start-up of the engine [1-3]. Their increasing use for energy storage is due to a number of factors including (i) their high power densities $(>10 \mathrm{~kW} / \mathrm{kg})$, (ii) moderate energy density $(\sim 5-6 \mathrm{Wh} / \mathrm{kg})$, (iii) that they can be fully charged/discharged in a matter of seconds [4,5], (iv) the cost competitiveness of the materials that they are comprised of, (v) high charge/discharge efficiency, and (vi) their high cycle life, which is generally longer than the life of the device being powered.

Generally, EDLCs are made up of two symmetrical activated carbon electrodes that display symmetric charge/ discharge power capability over the complete range of potential operation (i.e., from the maximum rated voltage to near zero). Carbon/carbon supercapacitors can be used over the complete voltage range without damage for at least 1 million cycles [6]. Carbon-based electrodes are of great interest because they are light, of moderate cost, abundant, easy to process, and possess high electronic conductivity and high specific surface area (yielding high charge storage). A variety of different carbon nanostructures can be produced that have very high surface areas and a wide variety of physical properties, which allows targeting of different types of applications. Templated carbons [7], carbide-derived carbons (CDCs) [8-10], 'onion-like' carbons (OLCs) [11], carbon fabrics (cloth, fibers) [12], nanotubes [13], activated graphene [14] and nanohorns [15] have been used as electrodes for EDLC applications [16].

Batteries have much higher energy densities (up to $250 \mathrm{Wh} / \mathrm{kg}$ for Li-ion) than current commercial supercapacitors $(5 \mathrm{Wh} / \mathrm{kg})$ [17]. One approach to increase energy density of supercapacitors is with ionic liquid electrolytes that offer better electrochemical stability than that of the aqueous $(1.23 \mathrm{~V})$ and organic $(2.7 \mathrm{~V})$ electrolytes currently used. Ionic liquids (IL) - salts (mainly, organic) that are liquid at room temperature - are being explored as electrolytes for Electrical Energy Storage (EES) systems owing to their high thermal (up to $350^{\circ} \mathrm{C}$ ) and electrochemical (up to $6 \mathrm{~V})$ stability [18]. Their high heat capacity, a large cohesive energy, and negligible vapor pressure at elevated temperatures make them safe and non-flammable electrolytes. This is especially important in energy storage applications when devices need to perform under extreme temperature conditions that can raise/cause safety issues. The raison d'être for exploring eutectic mixtures of ionic liquids is their large stable liquidus temperature range (the span of temperatures between the freezing point and boiling point of a liquid, such as from $-80^{\circ} \mathrm{C}$ to $\geq 250^{\circ} \mathrm{C}$ ). The size and symmetry of cations strongly influence the melting points of ionic liquids. Usually, one of the two pairing ions (usually the cation) is particularly large and possesses a low degree of symmetry, leading to inefficient packing of the large irregular cations with small charge-delocalized anions, which is why organic salts have a reduced crystal lattice energy and hence a lower melting point compared to inorganic salts [19]. Binary and ternary eutectic mixtures have been studied for EES systems. Binary eutectic systems first appeared with the discovery by Wilkes et al. in 1982 of a MeEtImCl/ $\mathrm{AlCl}_{3}$ molten salt mixture that was liquid over a wide range of compositions and to temperatures as low as $-98{ }^{\circ} \mathrm{C}$ for a composition of $67 \% \mathrm{AlCl}_{3}$ [20]. Other binary systems have been investigated by $\mathrm{Hou}$ et al. [21] using imidazolium-based ILs with organic salts. Every et al. [22] reported a eutectic mixture of pure ILs (mixing ethylmethyl-immidazolium tri-fluorosulfonyl-imide (EMI-TFSI) and $\mathrm{EMI}_{-} \mathrm{CF}_{3} \mathrm{SO}_{3}^{-}$(triflate)) with no evidence of a melting point, indeed only a glass transition was observed. Pyrrolidinium-based mixtures with TFSI-FSI-based ILs were also found by differential scanning calorimetry to form eutectic mixtures [23]. Deeper eutectics $\left(-95^{\circ} \mathrm{C}\right)$ were however observed to be mainly in mixtures of a common cation with two different anions compared to eutectics $\left(-25^{\circ} \mathrm{C}\right)$ in mixtures of a common anion with two different cations. Other binary systems include IL-LiX mixtures as electrolytes for battery applications [24-26]. Henderson et al. [24] reported decreasing the eutectic temperatures of pyrrolidinium-based ILs by using different alkyl chain lengths and Li salt concentrations.

As reported before, we have designed IL mixtures with exactly the same anion (FSI) but two different cations: piperidinium (PIP) and pyrrolidinium (PYR) [27]. These cations have the same molecular weight and the same number of atoms of the same nature, with the only difference being their cation molecular structure, namely a five-member (piperidinium) or six-member (pyrrolidinium) heterocycle. Methyl+propyl substituent groups (total of 4 carbons on side chains) are used for synthesizing the PIPbased cation and methyl + butyl substituent groups (total of 5 carbons on side chains) for synthesizing the PYR-based cation. The concept is to maintain similar intermolecular interactions due to the similar constituent atoms of the two cations, while also increasing disorder and asymmetry among the cations to hinder lattice formation to lower the melting point, but still maintaining good miscibility. Amongst common anions such as hexafluorophosphate $\left(\mathrm{PF}_{6}^{-}\right)$, tetrafluoroborate $\left(\mathrm{BF}_{4}^{-}\right)$, bis(trifluorosulfonyl)imide $\left(\mathrm{TFSI}^{-}\right)$ and bis(fluorosulfonyl)imide ( $\mathrm{FSI}^{-}$) anions, the imides (TFSI ${ }^{-}$ and $\mathrm{FSI}^{-}$) have emerged as popular alternatives to the $\mathrm{PF}_{6}^{-}$ and $\mathrm{BF}_{4}^{-}$anions due to the susceptibility of the $\mathrm{PF}_{6}^{-}$and $\mathrm{BF}_{4}^{-}$ anions to hydrolysis, leading to the production of hazardous hydrogen fluoride [28-32]. This is why hydrophobic TFSI ${ }^{-}$and $\mathrm{FSI}^{-}$anions are increasingly being studied as electrolytes for energy storage [33-35]. The $\mathrm{FSI}^{-}$ion has been selected to be the anion for the electrolyte used in this study due to its generally higher conductivity and lower viscosity as compared to the TFSI ${ }^{-}$ion when paired with the same cation [36], because of the smaller size and hence higher mobility of the $\mathrm{FSI}^{-}$ion. Cations were chosen by comparing their stability. The electrochemical stability of commonly used cations of ILS decreases in the order of Ammonium $\approx$ Piperidinium $\geq$ Pyrrolidinium $>$ Imidazolium [37]. Hence, cations with functional groups of pyrrolidinium (PYR) and piperidinium (PIP) with relatively higher electrochemical stability were explored.

A eutectic mixture composed of $(1: 1$ by weight or molar ratio) $\mathrm{N}$-methyl-N-propylpiperidinium bis(fluorosulfonyl)imide ( $\left.\mathrm{PIP}_{13}-\mathrm{FSI}\right)$ and $\mathrm{N}$-butyl-N-methylpyrrolidinium bis(fluorosulfonyl)imide ( PYR $\left._{14}-\mathrm{FSI}\right)$ was prepared and used as electrolyte. The measured melting points of constituents of this IL mixture were $6{ }^{\circ} \mathrm{C}\left(\mathrm{PIP}_{13}-\mathrm{FSI}\right)$ and $-18^{\circ} \mathrm{C}\left(\mathrm{PYR}_{14}-\mathrm{FSI}\right)$, in good agreement with 
published data [23]. The liquid state of this IL eutectic mixture can be maintained at temperatures several tens of degrees lower compared to the individual ILs. Mixing $\mathrm{PIP}_{13}-\mathrm{FSI}$ with $\mathrm{PYR}_{14}-\mathrm{FSI}$ resulted in an IL with two different cationic species and only one anion (namely, $\left.\left(\mathrm{PIP}_{13}-\mathrm{FSI}\right)_{0.5}\left(\mathrm{PYR}_{14}-\mathrm{FSI}\right)_{0.5}\right)$, which expands the liquid range to $-80^{\circ} \mathrm{C}$ as reported previously [27]. Most importantly, the wide electrochemical stability window is preserved in the mixtures, which contributes to the goal of increasing energy density, as $E=1 / 2 C V^{2}$, where $C$ is capacitance and $V$ is voltage. This electrolyte mixture was used in our previous work with nanostructured carbon electrodes of either onion-like carbon (OLC) or carbon nanotubes (CNTs) [27]. Excellent capacitive behavior has been observed in an extended operating temperature range of $-50{ }^{\circ} \mathrm{C}$ to $100{ }^{\circ} \mathrm{C}$. However, the specific capacitance obtained in these exohedral carbons was low ( $\sim 30 \mathrm{~F} / \mathrm{g} ; 4 \mathrm{mF} / \mathrm{cm}^{2}$ ), because of their moderate SSA and highly graphitic surface. This suggests increasing SSA and improving the carbon/electrolyte interface to increase the magnitude and quality of charge storage, thereby further improving the energy density and in an extended operating temperature range. However, nanoporous activated or carbidederived carbons that possess a high SSA and show excellent performance in organic electrolytes, show poor capacitive performance with IL electrolytes at room temperature or below $[10,27,34]$ due to low mobility of ions in porous networks. To the best of our knowledge, no carbon electrode material has ever shown capacitance of $100 \mathrm{~F} / \mathrm{g}$ or higher in any IL electrolyte below room temperature.

Ruoff's group recently reported on the activation of microwave exfoliated graphite oxide ('MEGO') using potassium hydroxide [38]. This carbon ('a-MEGO') had unique structure and properties, such as high SSA, approaching and even exceeding that of single-layer graphene, as measured by the Brunauer-Emmett-Teller (BET) method [39], along with a continuous, three dimensional pore structure consisting of atom-thick walls and both micro- and mesopores. It showed high capacitance in IL electrolyte at room temperature, but has not been tested at low temperatures. Since a-MEGO possesses high electrical conductivity, low 0 and $\mathrm{H}$ content, and is composed mostly of $\mathrm{sp}^{2}$ bonded carbon, we reasoned that it might yield a dramatic increase in specific capacitance, compared to OLC or CNTs, with the $\left(\mathrm{PIP}_{13}-\mathrm{FSI}\right)_{0.5}\left(\mathrm{PYR}_{14}-\mathrm{FSI}\right)_{0.5}$ ionic liquid electrolyte.

\section{Experimental}

The synthesis procedure for a-MEGO, as well as its structure, has been described in Ref. [38]. MEGO was prepared from graphite oxide (GO) by microwave irradiation [40], then dispersed and soaked in aqueous $\mathrm{KOH}$ solution for $20 \mathrm{~h}$. The solid cake obtained after vacuum filtration of the excess $\mathrm{KOH}$ was then dried. The dry $\mathrm{MEGO} / \mathrm{KOH}$ mixture was heated at $800{ }^{\circ} \mathrm{C}$ for $1 \mathrm{~h}$ in a horizontal tube furnace with an argon flow of $150 \mathrm{sccm}$ at atmospheric pressure. The sample was then washed with de-ionized water, and dried at $65^{\circ} \mathrm{C}$ in ambient air for $2 \mathrm{~h}$. Annealing of activated graphene was done in a custom made vacuum furnace (Solar Atmospheres, USA) at $1100^{\circ} \mathrm{C}$, with the heating ramp $10^{\circ} \mathrm{C} / \mathrm{min}$, and a vacuum $\sim 10^{-6}$ Torr for $10 \mathrm{~min}$.

Nitrogen gas sorption was performed at $77 \mathrm{~K}$ using a Quadrasorb Pore Size and Surface Area Analyzer
(Quantachrome Instruments, USA). Prior to analysis, samples were outgassed at $200{ }^{\circ} \mathrm{C}$ in vacuum at about $10^{-2} \mathrm{Torr}$ for $24 \mathrm{~h}$. Surface area was calculated using the BET method in the range of $0.05-0.3 P / P_{0}$. Pore size distributions (PSD) were determined using the quenched solid density functional theory (QSDFT) model, assuming a slit pore geometry, which was part of the QuadraWin software package (Quantachrome Instruments, USA).

Raman spectra were recorded with an Invia confocal Raman spectrometer (Renishaw, UK) using a laser with an excitation wavelength of $514.5 \mathrm{~nm}$ and having a spot size of $2 \mu \mathrm{m}$.

ILs were prepared at Solvionic SA (France). N-methyl-Nbutylpyrrolidinium bromide, $\mathrm{PYR}_{14}-\mathrm{Br}$, is first produced from the quarternization of methyl-pyrrolidine by 1 -bromobutane to yield its halide salt, $\mathrm{PYR}_{14}-\mathrm{Br}$. The desired $\mathrm{PYR}_{14}-\mathrm{FSI} I \mathrm{~L}$ was then obtained through the anionic exchange of the $\mathrm{Br}^{-}$ with potassium bis(fluorosulfonyl)imide (KFSI). N-methyl$\mathrm{N}$-propylpiperidinium bromide, $\mathrm{PIP}_{13}-\mathrm{Br}$, was obtained from the quarternization of $\mathrm{N}$-methyl- $\mathrm{N}$-propylpiperidine by 1-bromopropane to yield its halide salt, $\mathrm{PIP}_{13}-\mathrm{Br}$ and the subsequent metathesis (with KFSI) to obtain the product $\mathrm{PIP}_{13}$-FSI. The eutectic IL mixture (1:1 by weight) was then obtained by mixing $\mathrm{N}$-methyl- $\mathrm{N}$-propylpiperidinium bis(fluorosulfonyl)imide $\left(\mathrm{PIP}_{13} \mathrm{FSI}\right)$ and $\mathrm{N}$-butyl-N-methylpyrrolidinium bis(fluorosulfonyl)imide ( $\mathrm{PYR}_{14} \mathrm{FSI}$ ) [27].

Microcavity electrode measurements that have been described in our previous work $[11,41]$ were done on the aMEGO powders under glovebox conditions of $<0.1 \mathrm{ppm}$ of water and oxygen content. A two-electrode Swagelok ${ }^{\mathbb{R}}$ nylon cell with stainless steel pistons was used for quantitative electrochemical characterizations of as-activated MEGO (i.e., a-MEGO) powders, and a three-electrode Swagelok ${ }^{\mathbb{R}}$ nylon cell was used to characterize vacuum annealed a-MEGO powders. Each cell was assembled in the eutectic mixture of ILs under glove-box conditions. Pt disks were placed onto stainless steel current collectors to decrease the contact resistance at the as-activated a-MEGO/piston interface. A silver wire was used as a quasi-reference electrode. The as-activated a-MEGO, electrode films (disks) of $1.1 \mathrm{~cm}^{2}, 1.65 \mathrm{mg}$, and $55 \mu \mathrm{m}$ thick were made of $95 \%$ of the carbon powder and $5 \%$ of PTFE (Dupont de Nemours) binder as described in Zhu et al. [38], whereas for the annealed a-MEGO, the powder was tested directly without film processing. Electrodes were wetted with the electrolyte and covered by two layers of $25 \mu \mathrm{m}$-thick porous $\mathrm{Al}_{2} \mathrm{O}_{3}$ separator (Separion ${ }^{\circledR}$, average pore size of $240 \mathrm{~nm},>40 \%$ porosity, Evonik Industries, Germany); these separators were wetted by the electrolyte prior to being placed between the electrodes. Swagelok ${ }^{\mathbb{R}}$ cells were kept under light pressure during the measurement to buffer thermal expansion/contraction of the stainless steel pistons. Temperature control was achieved using a Votsch climatic chamber (Germany) with the temperature being additionally checked by a thermocouple. After heating to a certain temperature, the system was kept isothermal for a period of no less than $5 \mathrm{~h}$ prior to electrochemical measurements to ensure system equilibration. For low temperature experiments, this dwell time was increased to an overnight period $(>6 \mathrm{~h})$.

Capacitance was calculated from cyclic voltammetry (CV) by measuring the slope of a charge $Q$ versus voltage $(V)$ plot. Charge was calculated from the integration of the area under the voltammogram obtained in discharge. 
The current in the CVs in Figs. 3a, 4a, c, and 5b was normalized by dividing the current values by the potential scan rate to obtain capacitance $(C)$.

\section{Results and discussion}

Single-layer graphene has a theoretical specific surface area of $2630 \mathrm{~m}^{2} / \mathrm{g}$ however in practice the BET SSA is generally much lower because of multi-layer sheets and agglomeration. We approach the theoretical value of a single sheet of graphene, with as-activated a-MEGO having a high surface area of $1901 \mathrm{~m}^{2} / \mathrm{g}$ and all pores less than $5 \mathrm{~nm}$ (Figure 1a). The a-MEGO was vacuum annealed at $1100{ }^{\circ} \mathrm{C}$ in an attempt to remove the oxygen containing surface functional groups. At this temperature (and for the 'right' exposure time), one might expect that oxygen containing groups would be removed while the structure of the a-MEGO might be preserved. From Figure 1b, after annealing, the BET SSA is $1586 \mathrm{~m}^{2} / \mathrm{g}$, and the peak in the PSD around $3.25 \mathrm{~nm}$ is smaller than that of the as-activated a-MEGO. The microporous region $(<2 \mathrm{~nm})$ was unchanged after annealing, indicating the initial pore structure in a-MEGO has been largely preserved. The vacuum annealed a-MEGO has a desirable PSD for supercapacitors, as it has both micropores that give it a high SSA, in the range of values typical for activated carbons, and mesopores that facilitate ion mobility during charging and discharging.

Comparing the pore structure of vacuum annealed a-MEGO to the as-activated a-MEGO material that was recently reported and tested in supercapacitors at room temperature [38], the pore size distribution of the vacuum annealed a-MEGO made here tends to a smaller average pore size and a smaller specific surface area, with the previously reported a-MEGO having a 'high end' value of BET SSA of $\sim 3100 \mathrm{~m}^{2} / \mathrm{g}$ [38]. Both materials have all pores less than $10 \mathrm{~nm}$. Other materials for supercapacitors, such as CDC and activated carbon, have similar surface areas to vacuum annealed a-MEGO, but tend to have an intricate network of pores that limits ion transport rates and prevents fast charging and discharging when viscous IL electrolytes are used $[27,34]$.
The disorder and graphitic nature of the structure before and after annealing was analyzed using Raman spectroscopy (Figure 2). There is very little difference in the two spectra, implying the annealing process did not change the graphene layer structure. The main difference lies in the full width at half maximum (FWHM) of the disorder-induced (D) band, which narrows after annealing from 160 to $140 \mathrm{~cm}^{-1}$, implying healing of some defects. The main goal of annealing the a-MEGO was to remove oxygen groups on the surface without affecting a-MEGO structure, which seems to be successful from the Raman spectra as the difference before and after annealing is subtle.

Figure $3 a$ shows the $\mathrm{CV}$ scanned at $20 \mathrm{mV} / \mathrm{s}$ at room temperature of the as-activated a-MEGO electrodes in the IL mixture presented in terms of capacitance versus voltage of the cell. This again confirms the feasibility of using the eutectic IL mixture with as-activated a-MEGO and annealed a-MEGO, in addition to the previous OLCs and CNTs [27] that have been tested. A maximum operating voltage of $3.5 \mathrm{~V}$ (same as for the OLCs) [27] was obtained at room temperature with a capacitance of $\sim 160 \mathrm{~F} / \mathrm{g}$, a 5-fold increase compared to

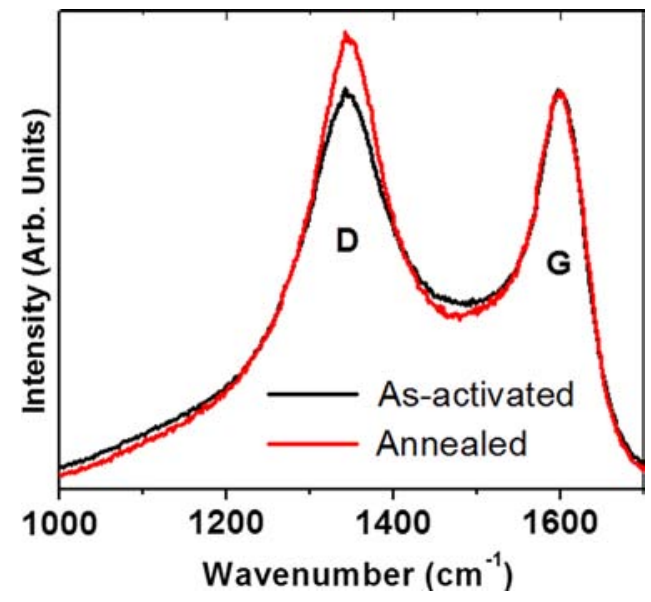

Figure 2 Raman spectra of as-a-MEGO in the carbon spectral range showing the bands corresponding to disordered structures (D) around $1350 \mathrm{~cm}^{-1}$ and in-plane vibrations of graphite (G) around $1600 \mathrm{~cm}^{-1}$. Note that there is no significant change of the structure as a result of annealing.

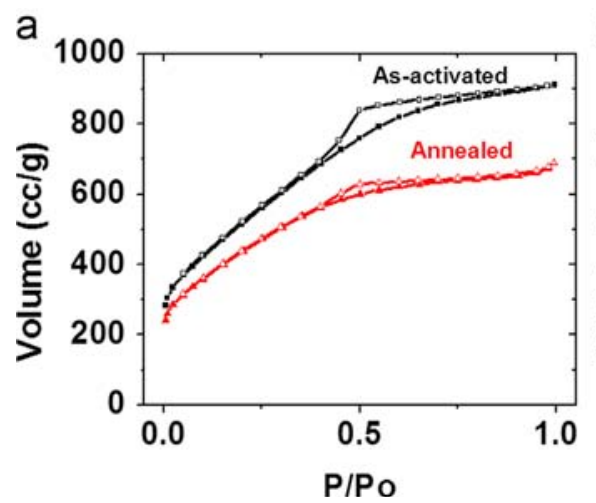

b

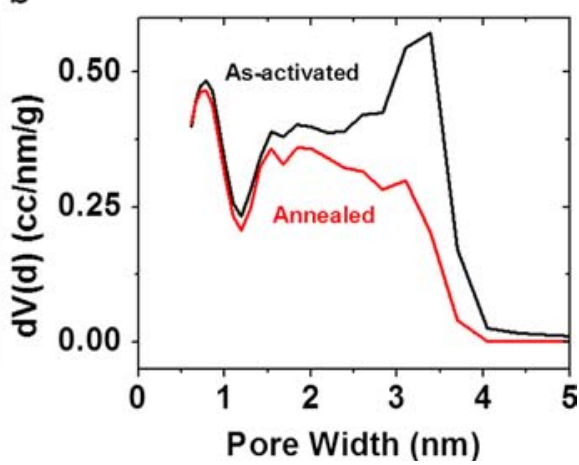

Figure 1 Nitrogen sorption isotherms (a) and corresponding pore size distributions (b) for as-activated (BET SSA $1900 \mathrm{~m}^{2} / \mathrm{g}$ ) and vacuum annealed a-MEGO (BET SSA $1590 \mathrm{~m}^{2} / \mathrm{g}$ ). After annealing, there is a decrease in the volume of small mesopores around $3 \mathrm{~nm}$, while the micropores within a-MEGO are preserved. Closed symbols in (a) represent the adsorption branch while open symbols represent the desorption branch. 
a

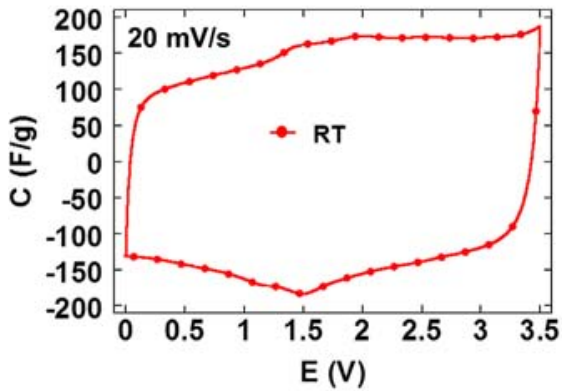

b

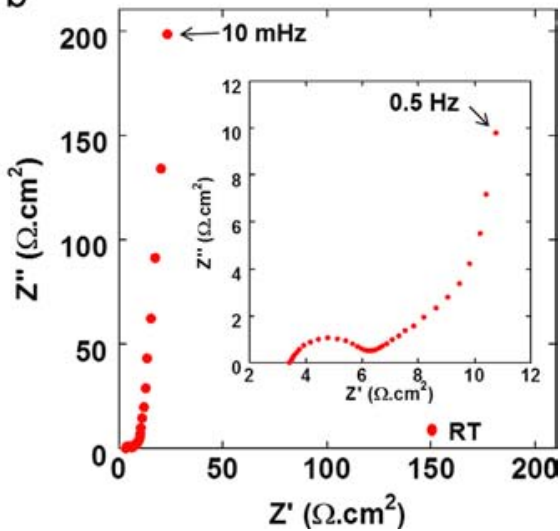

Figure 3 Room temperature electrochemical characterization of a-MEGO electrodes in $\left(\mathrm{PIP}_{13}-\mathrm{FSI}_{0.5}\left(\mathrm{PYR}_{14}-\mathrm{FSI}\right)_{0.5}\right.$ electrolyte: $\mathrm{CVs}$ collected at $20 \mathrm{mV} / \mathrm{s}$ with the electrochemical window of $3.5 \mathrm{~V}$ and showing capacitance of $150 \mathrm{~F} / \mathrm{g}$ (a) and the corresponding EIS Nyquist plot (b). Inset in (b) shows data at the high-frequency range.

a

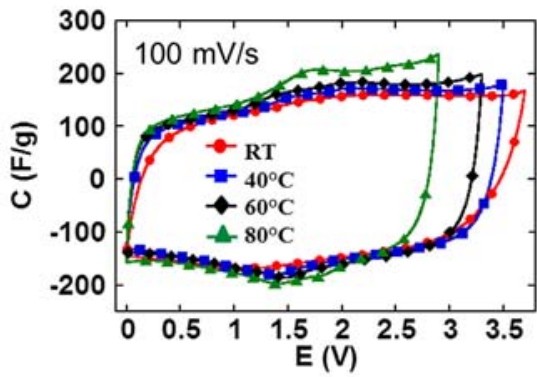

C

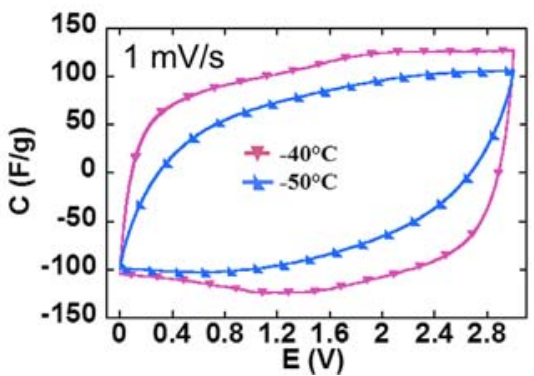

b

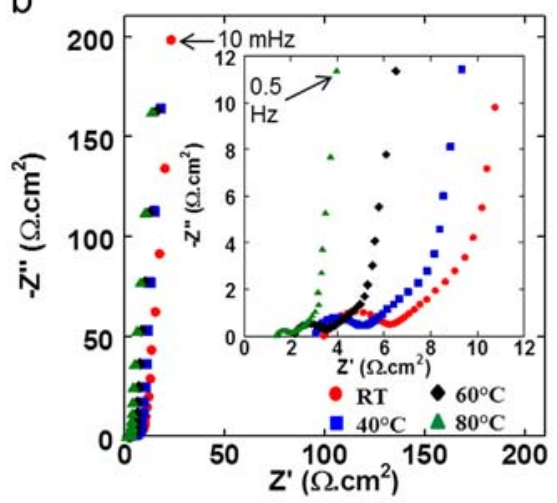

d

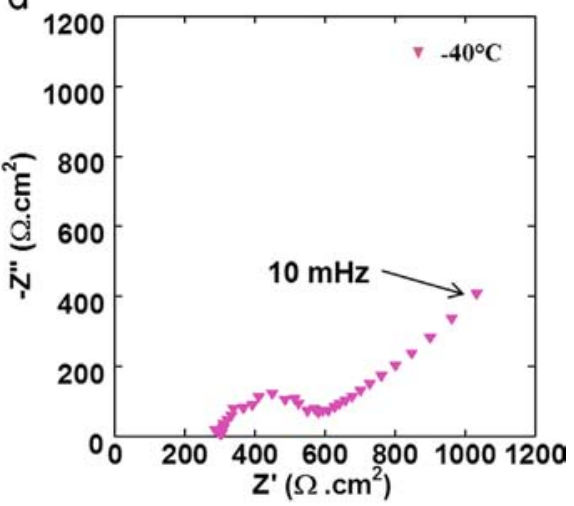

Figure 4 Electrochemical characterization of a-MEGO electrodes in $\left(\mathrm{PIP}_{13}-\mathrm{FSI}\right)_{0.5}\left(\mathrm{PYR}_{14}-\mathrm{FSI}\right)_{0.5}$ electrolyte: CVs collected at $100 \mathrm{mV} / \mathrm{s}(\mathrm{a})$, corresponding EIS Nyquist plots (b) at room and elevated temperatures $\left(\mathrm{RT} \leq T \leq 80{ }^{\circ} \mathrm{C}\right)$, and $\mathrm{CVs}$ collected at $1 \mathrm{mV} / \mathrm{s}$ $\left(T \leq-40^{\circ} \mathrm{C}\right)(\mathrm{c})$ and the corresponding EIS Nyquist plot at $T=-40^{\circ} \mathrm{C}$ (d).

OLCs and CNTs ( $\sim 30 \mathrm{~F} / \mathrm{g})$ [27]. This huge increase can be firstly attributed to the SSA of the as-activated a-MEGO electrodes, which is at least 4 times larger than that of OLC $\left(\sim 400 \mathrm{~m}^{2} / \mathrm{g}\right)$. Moreover, the open inter-layer porosity (up to $4 \mathrm{~nm}$ ) of the asactivated a-MEGO electrodes allows electrolyte ions access to the subnanometer pores in a-MEGO sheets without much limitation in ion transfer, as may occur when using conventional activated carbons with a tortuous pore network and narrow bottlenecks between pores [27].

Figure $3 \mathrm{~b}$ shows the EIS plot for the a-MEGO electrodes assembled in the ionic liquid mixture. The vertical increase of the imaginary part of the impedance provides evidence of the capacitive storage achieved with a-MEGO. A fairly low ESR of $3.4 \Omega \mathrm{cm}^{2}$ (intercept of the X-axis at high frequency) 

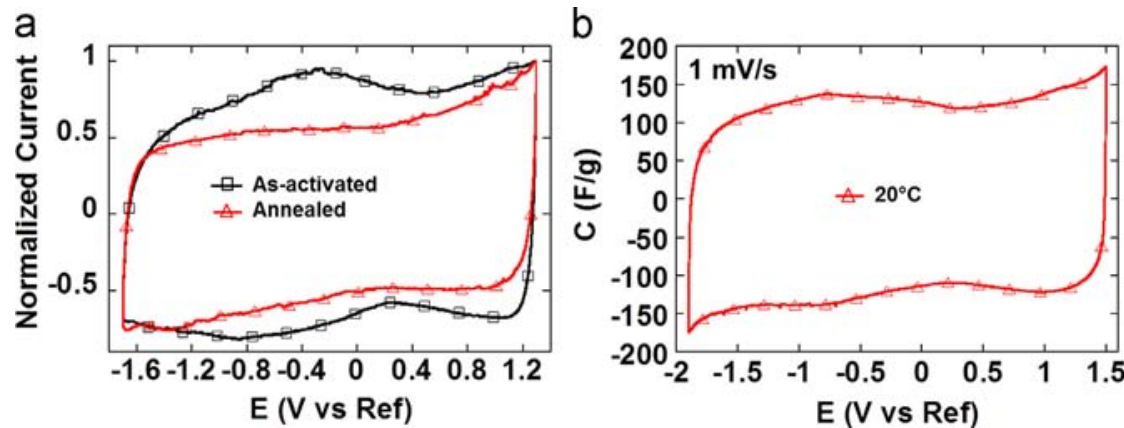

Figure 5 Cyclic voltammograms of annealed and as-activated a-MEGO electrodes in $\left(\mathrm{PIP}_{13}-\mathrm{FSI}_{0.5}\left(\mathrm{PYR}_{14}-\mathrm{FSI}\right)_{0.5}\right.$ electrolyte: $\mathrm{CVs}$ collected at $500 \mathrm{mV} / \mathrm{s}$ at room temperature using CME (a); CV collected at $1 \mathrm{mV} / \mathrm{s}$ using a Swagelok ${ }^{\circledR}$ cell (b).

was measured at room temperature $\left(10 \Omega \mathrm{cm}^{2}\right.$ ESR was measured for CNT electrodes [27]), mainly due to the high electrical conductivity of the a-MEGO electrode $(500 \mathrm{~S} / \mathrm{cm})$ compared to commercial activated carbons $(0.1-1 \mathrm{~S} / \mathrm{cm})$ [42]. Since both sides of the atom-thick pore walls of a-MEGO (graphene-like layers) can be used in charge storage, once the electrolyte gains access to these surfaces, a tremendous amount of charge could be stored as observed in the 5-fold increase in capacitance using a-MEGO instead of OLCs. This capacitance value is in agreement with the value reported by Zhu et al. [38] using neat EMI-TFSI with as-activated a-MEGO electrodes.

Capacitance at Elevated Temperature $\left(20 \leq T \leq 80^{\circ} \mathrm{C}\right)$ : Figure $4 \mathrm{a}$ shows CVs recorded at $100 \mathrm{mV} / \mathrm{s}$ to their respective maximum voltages at different temperatures. There is a gradual increase of capacitance (area under the CV curve) with increasing temperature that can be explained by the higher ionic conductivity (ion mobility) of the electrolyte at elevated temperatures, which is also reflected in the more rectangular shape of the CVs with increasing temperature. Electrochemical impedance measurements further confirm the decrease in ionic resistance as shown in Figure $4 \mathrm{~b}$ and the ESR value decreases from 3.4 to $1.3 \Omega \mathrm{cm}^{2}$ upon increasing the temperature from $20^{\circ} \mathrm{C}$ to $80{ }^{\circ} \mathrm{C}$. The capacitance increases from 160 to $180 \mathrm{~F} / \mathrm{g}$ as temperature increases from RT to $80^{\circ} \mathrm{C}$. The operating voltage is limited to $2.9 \mathrm{~V}$ at $80^{\circ} \mathrm{C}$, which is linked with the enhanced electrolyte electrochemical activity at platinum current collectors at elevated temperature (see Supplementary Figure S1).

Capacitance at sub-zero temperatures $\left(-40\right.$ and $\left.-50^{\circ} \mathrm{C}\right)$ : Figure $4 \mathrm{C}$ shows the $\mathrm{CVs}$ recorded at sub-zero temperatures of -40 and $-50{ }^{\circ} \mathrm{C}$. About $70 \%$ of the capacitance is still retained at $1 \mathrm{mV} / \mathrm{s}$ (which is a reasonable scan rate taking into account the reduced ion mobility for such low temperatures) and the CVs show good capacitive behavior at $-40{ }^{\circ} \mathrm{C}$ with high capacitance values of 100 to $120 \mathrm{~F} / \mathrm{g}$ obtained when charged to $3 \mathrm{~V}$. Such retention of capacitance over this wide operating temperature range (from $-50{ }^{\circ} \mathrm{C}$ to $80^{\circ} \mathrm{C}$ ) with capacitance always above $100 \mathrm{~F} / \mathrm{g}$, to our knowledge, has never been reported before in the literature [43-48]. EIS measurements still show a capacitive behavior, despite the presence of an expected extra semicircle at high frequency, attributed to the onset of gelation that is related to decreased mobility of the electrolyte ions within the pores of a-MEGO at such low temperatures

Table 1 Capacitance of annealed a-MEGO electrodes in $\left(\mathrm{PIP}_{13}-\mathrm{FSI}\right)_{0.5}\left(\mathrm{PYR}_{14}-\mathrm{FSI}\right)_{0.5}$ electrolyte at room temperature.

Scan rate $(\mathrm{mV} / \mathrm{s})$

Charging/discharging capacitance

$(F / g)$

\begin{tabular}{rr}
\hline 20 & 100 \\
5 & 110 \\
1 & 130 \\
\hline
\end{tabular}

[49-51]. The capacitive behavior of a-MEGO decreases at $-50{ }^{\circ} \mathrm{C}$ which is evident by a less rectangular $\mathrm{CV}$ than that seen in the CNTs.

While the a-MEGO electrodes show outstanding capacitance of $\sim 180 \mathrm{~F} / \mathrm{g}$ (see Figure $3 \mathrm{a}$ ), the presence of bumps in the $\mathrm{CV}$ at about $1.5 \mathrm{~V}$ could be due to electrochemically active oxygen-containing functional groups, such as carboxylic acid or hydroxyl groups on their surface. Such bumps were also observed when a-MEGO electrodes were tested in EMI-TFSI electrolyte [38]. Although they are suitable for improving the capacitance, such surface groups are known to be unstable during cycling, thus limiting the cycle life of the cells [16]. This motivated annealing a-MEGO powder at $1100{ }^{\circ} \mathrm{C}$ under vacuum to try to eliminate functional groups that may be present on its surface. Annealed and asactivated a-MEGO powders were tested in the eutectic IL mixture at room temperature using a microcavity electrode to obtain information on any difference in electrochemical response as a result of vacuum annealing. The CVs collected from both samples in a 3-electrode cell are shown in Figure $5 \mathrm{a}$, scanned within a potential window of -1.7 to $1.3 \mathrm{~V} /$ Ref. Bumps observed at $\sim-0.3 \mathrm{~V} /$ Ref in the positive scan and at $\sim-0.8 \mathrm{~V} /$ Ref in the negative scan are pronounced for the as-activated a-MEGO powder and clearly decreased after annealing.

Annealed a-MEGO powders were then characterized in Swagelok ${ }^{\circledR}$ cells, using a 3 -electrode configuration. Figure $5 \mathrm{~b}$ shows the $\mathrm{CV}$ of annealed a-MEGO powders at $1 \mathrm{mV} / \mathrm{s}$ at room temperature. Note that in these experiments, raw powders were tested without any binder so that the ohmic drop was not optimized in the cell which is why a low scan rate was used. Annealed a-MEGO powders reached a capacitance of $130 \mathrm{~F} / \mathrm{g}$, which is $\sim 20 \%$ less than the 
capacitance obtained for the as-activated samples, as expected from a lower SSA of the annealed material. The other point to be taken into account is the processing of the electrode, which could have some effect on capacitance values measured (Figure 5b). In conclusion, the high capacitance of the a-MEGO materials observed in the ionic liquid mixture can be primarily associated with double layer charging as shown in Table 1.

\section{Conclusions}

The electrochemical characterization of as-activated and vacuum annealed a-MEGO has been carried out in a eutectic mixture of ionic liquids, $\left(\mathrm{PIP}_{13}-\mathrm{FSI}\right)_{0.5}\left(\mathrm{PYR}_{14}-\mathrm{FSI}\right)_{0.5}$. Annealing the a-MEGO yields better electrochemical stability, but the specific capacitance somewhat decreases due to decreased mesoporosity and associated accessible SSA after annealing.

For ionic liquid electrolytes, an exceptionally high capacitance of about $150 \mathrm{~F} / \mathrm{g}$, with a maximum voltage of $3.5 \mathrm{~V}$ was attained over an unprecedented $130^{\circ} \mathrm{C}$ (from -50 to $80^{\circ} \mathrm{C}$ ) temperature window. This is 5 times higher capacitance compared to exohedral nanostructured carbon (nanotubes and onions) electrodes in the same eutectic mixture of ionic liquids. These findings have largely overcast the temperature range offered by conventional organic electrolytes of $110{ }^{\circ} \mathrm{C}$ (from $-30^{\circ} \mathrm{C}$ to $80^{\circ} \mathrm{C}$ ) and would greatly contribute to the advances in electrical storage based on ILs, pushing the limits of energy storage to greater heights. These studies have not only affirmed our previous findings on the need to design carbon structure for optimizing carbon/electrolyte interface, but also showed that ionic liquids are no longer confined to the category of "above room temperature" applications. Even more, they have proved their extended threshold for extreme climatic conditions, which clearly proves the robustness of ILs as electrolytes for electrical storage.

Herein, the research pathway has been paved towards optimizing the carbon accessible surface area (e.g., by using activated graphene, i.e., a-MEGO [38], de-bundled singlewalled nanotubes [52], or mesoporous templated carbons [53]) together with designing the IL-based electrolyte. Control of the electrolyte composition and its molecular/ ionic structure is required for achieving better compatibilities with various carbon structures and surpassing the current capacitance and energy density limits of EES.

\section{Acknowledgments}

P. Simon would like to thank the European Research Council for supporting the research (Advanced Grant no. ERC-2011AdG, Project no. 291543 - IONACES); W.-Y. Tsai was fully supported by the ERC Grant. Y. Gogotsi and J. McDonough were supported as part of the Fluid Interface Reactions, Structures and Transport (FIRST) Center, an Energy Frontier Research Center funded by the US Department of Energy, Office of Science, Office of Basic Energy Sciences. Work at UT Austin was supported by the US Department of Energy (DOE) under Award no. DE-SC001951.

\section{Appendix A. Supporting information}

Supplementary data associated with this article can be found in the online version at http://dx.doi.org/10.1016/ j.nanoen.2012.11.006.

\section{References}

[1] R. Kotz, M. Carlen, Electrochimica Acta 45 (2000) 2483-2498.

[2] A. Burke, Journal of Power Sources 91 (2000) 37-50.

[3] R.J. Brodd, K.R. Bullock, R.A. Leising, R.L. Middaugh, J.R. Miller, E. Takeuchi, Journal of the Electrochemical Society 151 (2004) K1-K11.

[4] J.R. Miller, P. Simon, Science 321 (2008) 651-652.

[5] P. Simon, Y. Gogotsi, Nature Materials 7 (2008) 845-854.

[6] M. Everett, Ultracapacitors: a mature energy-storage alternative in a dramatically expanding application set, Maxwell Technologies, in: Proceedings of the AABC Conference, Mainz, Germany, June 18-22, 2012.

[7] A. Kajdos, A. Kvit, F. Jones, J. Jagiello, G. Yushin, Journal of the American Chemical Society 132 (2010) 3252-3253.

[8] A. Janes, E. Lust, Journal of the Electrochemical Society 153 (2006) A113-A116.

[9] B.D. Shanina, A.A. Konchits, S.P. Kolesnik, A.I. Veynger, A.M. Danishevskii, V.V. Popov, S.K. Gordeev, A.V. Grechinskaya, Carbon 41 (2003) 3027-3036.

[10] V. Presser, M. Heon, Y. Gogotsi, Advanced Functional Materials 21 (2011) 810-833.

[11] C. Portet, J. Chmiola, Y. Gogotsi, S. Park, K. Lian, Electrochimica Acta 53 (2008) 7675-7680.

[12] K. Okajima, K. Ohta, M. Sudoh, Electrochimica Acta 50 (2005) 2227-2231.

[13] D.N. Futaba, K. Hata, T. Yamada, T. Hiraoka, Y. Hayamizu, Y. Kakudate, O. Tanaike, H. Hatori, M. Yumura, S. lijima, Nature Materials 5 (2006) 987-994.

[14] M.D. Stoller, S. Park, Y. Zhu, J. An, R.S. Ruoff, Nano Letters 8 (2008) 3498-3502.

[15] C.-M. Yang, Y.-J. Kim, M. Endo, H. Kanoh, M. Yudasaka, S. lijima, K. Kaneko, Journal of the American Chemical Society 129 (2007) 20-21.

[16] A.G. Pandolfo, A.F. Hollenkamp, Journal of Power Sources 157 (2006) 11-27.

[17] J.-M. Tarascon, M. Armand, Nature 414 (2001) 359-367.

[18] M. Galiński, A. Lewandowski, I. Stępniak, Electrochimica Acta 51 (2006) 5567-5580.

[19] C.A. Angell, W. Xu, M. Yoshizawa, A. Hayashi, J.-P. Belieres, P. Lucas, M. Videa, in: H. Ohno (Ed.), Electrochemical Aspects of Ionic Liquids, first ed.,Wiley-Interscience, Hoboken, New Jersey, 2005 (Chapter 2).

[20] J.S. Wilkes, J.A. Levisky, R.A. Wilson, C.L. Hussey, Inorganic Chemistry 21 (1982) 1263-1264.

[21] Y. Hou, Y. Gu, S. Zhang, F. Yang, H. Ding, Y. Shan, Journal of Molecular Liquids 143 (2008) 154-159.

[22] H. Every, A.G. Bishop, M. Forsyth, D.R. MacFarlane, Electrochimica Acta 45 (2000) 1279-1284.

[23] M. Kunze, S. Jeong, E. Paillard, M. Winter, S. Passerini, Journal of Physical Chemistry C 114 (2010) 12364-12369.

[24] W.A. Henderson, S. Passerini, Chemistry of Materials 16 (2004) 2881-2885.

[25] Q. Zhou, P.D. Boyle, L. Malpezzi, A. Mele, J.-H. Shin, S. Passerini, W.A. Henderson, Chemistry of Materials 23 (2011) 4331-4337.

[26] K. Kubota, T. Nohira, T. Goto, R. Hagiwara, Electrochemistry Communications 10 (2008) 1886-1888. 
[27] R. Lin, P.-L. Taberna, S. Fantini, V. Presser, C.R. Pérez, F. Malbosc, N.L. Rupesinghe, K.B.K. Teo, Y. Gogotsi, P. Simon, Journal of Physical Chemistry Letters 2 (2011) 2396-2401.

[28] R.P. Swatloski, J.D. Holbrey, R.D. Rogers, Green Chemistry 5 (2003) 361-363.

[29] S.I. Lall, D. Mancheno, S. Castro, V. Behaj, J.I. Cohen, R. Engel, Chemical Communications 24 (2000) 2413-2414.

[30] L. Gubicza, N. Nemestothy, T. Frater, K. Belafi-Bako, Green Chemistry 5 (2003) 236-239.

[31] C. Villagran, M. Deetlefs, W.R. Pitner, C. Hardacre, Analytical Chemistry 76 (2004) 2118-2123.

[32] R.J. Bernot, M.A. Brueseke, M.A. Evans-White, G.A. Lamberti, Environmental Toxicology and Chemistry 24 (2005) 87-92.

[33] C. Arbizzani, M. Biso, D. Cericola, M. Lazzari, F. Soavi, M. Mastragostino, Journal of Power Sources 185 (2008) 1575-1579.

[34] C. Largeot, C. Portet, J. Chmiola, P.-L. Taberna, Y. Gogotsi, P. Simon, Journal of the American Chemical Society 130 (2008) 2730-2731.

[35] N. Handa, T. Sugimoto, M. Yamagata, M. Kikuta, M. Kono, M. Ishikawa, Journal of Power Sources 185 (2008) 1585-1588.

[36] M. Kunze, M. Montanino, G.B. Appetecchi, S. Jeong, M. Schonhoff, M. Winter, S. Passerini, Journal of Physical Chemistry A 114 (2010) 1776-1782.

[37] P. Wasserscheid, T. Welton, lonic Liquids, in Synthesis, second ed., WILEY-VCH, Weinheim, 2008.

[38] Y. Zhu, S. Murali, M.D. Stoller, K.J. Ganesh, W. Cai, P.J. Ferreira, A. Pirkle, R.M. Wallace, K.A. Cychosz, M. Thommes, D. Su, E.A. Stach, R.S. Ruoff, Science 332 (2011) 1537-1541.

[39] S. Brunauer, P.H. Emmett, E. Teller, Journal of the American Chemical Society 60 (1938) 309-319.

[40] Y. Zhu, S. Murali, M.D. Stoller, A. Velamakanni, R.D. Piner, R.S. Ruoff, Carbon 48 (2010) 2118-2122.

[41] R. Lin, P.-L. Taberna, J. Chmiola, D. Guay, Y. Gogotsi, P. Simon, Journal of the Electrochemical Society 156 (2009) A7-A12.

[42] L.L. Zhang, R. Zhou, X.S. Zhao, Journal of Materials Chemistry 20 (2010) 5983-5992.

[43] R. Kötz, M. Hahn, R. Gallay, Journal of Power Sources 154 (2006) 550-555.

[44] H. Kurig, A. Janes, E. Lust, Journal of the Electrochemical Society 157 (2010) A272-A279.

[45] V. Ruiz, T. Huynh, S.R. Sivakkumar, A.G. Pandolfo, RSC Advances 2 (2012) 5591-5598.

[46] C. Largeot, P.L. Taberna, Y. Gogotsi, P. Simon, Electrochemical and Solid-State Letters 14 (2011) A174-A176.

[47] E. Iwama, P.L. Taberna, P. Azais, L. Brégeon, P. Simon, Journal of Power Sources 219 (2012) 235-239.

[48] NASA technical reports sever. <http://naca.larc.nasa.gov/search. jsp?R=20100001352\& qs=N\%3D4294964234\%2B4294943931\%2B4294350901 >.

[49] J. Reiter, J. Vondrak, J. Michalek, Z. Micka, Electrochimica Acta 52 (2006) 1398-1408.

[50] E.J. Brandon, W.C. West, M.C. Smart, L.D. Whitcanack, G.A. Plett, Journal of Power Sources 170 (2007) 225-232.

[51] A.-K. Hjelm, T. Eriksson, G. Lindbergh, Electrochimica Acta 48 (2002) 171-179.

[52] A. Izadi-Najafabadi, S. Yasuda, K. Kobashi, T. Yamada, D.N. Futaba, H. Hatori, M. Yumura, S. lijima, K. Hata, Advanced Materials 22 (2010) E235-E241.

[53] T. Kyotani, J. Chmiola, Y. Gogotsi, in: F. Beguin, E. Frackowiak (Eds.), Carbon Materials for Electrochemical Energy Storage Systems, CRC Press/Taylor and Francis, Boca Raton, FL, 2009.

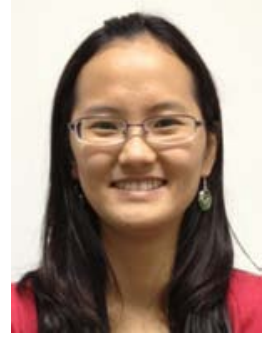

Wan-Yu Tsai received her B.S. in Materials Science and Engineering from National TsingHua University in Taiwan in 2008. Being awarded the Erasmus Mundus Scholarship, she joined the MESC (Materials for Energy Storage and Conversion) master program in 2009, and received her M.S in 2011. She is currently a PhD student in Paul Sabatier University (Toulouse, France), under Professor Simon and Professor Taberna's guidance. Her research is focused on EQCM study of ion adsorption at nanoporous carbon electrode for supercapacitor application.

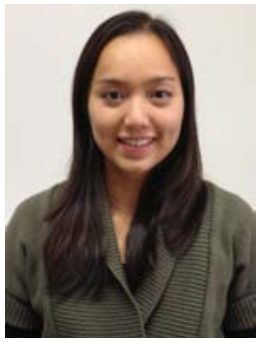

Rongying Lin was conferred a Bachelor of Applied Science in Materials Chemistry from the National University of Singapore (NUS) in 2004. She worked as a research assistant in NUS for one year before being awarded the Erasmus Mundus scholarship for MESC master program from 2006 to 2008. In 2012, she received her Ph.D. in Materials Science from the University of Paul Sabatier (France), achieved through industrial collaboration with SOLVIONIC. She is currently on a postdoctoral research position under the leadership of Professor Simon. Research includes electrochemical studies of electrolytes (ionic liquids and mixtures) and electrode materials for supercapacitors and batteries.

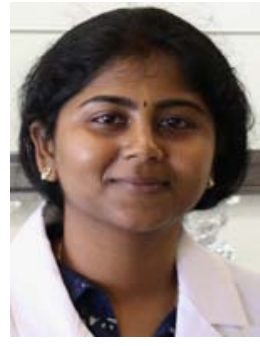

Shanthi Murali is currently doing thesis research in Materials Science and Engineering at The University of Texas at Austin under the direction of Prof. Rodney S. Ruoff. She received her M.S. in Chemical Engineering from Auburn University in 2008 where her thesis work involved liquid crystalline assembly of nanowires. Her current research includes studying the reduction of exfoliated graphite oxide, and energy storage in systems with graphene-based materials as the electrodes.

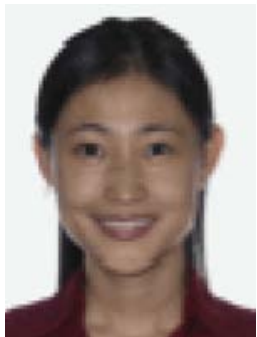

Dr. Li Li Zhang received her B. Eng. in Chemical and Biomolecular Engineering from the National University of Singapore in 2004. After two years industrial experiences in Micron, she continued her Ph.D. study in the same department at the National University of Singapore from 2006 and received her $\mathrm{Ph}$. D degree in 2011. She worked as a research engineer from 2010 to 2011 at NUS and now she works in Professor Ruoff's group as a postdoctoral research fellow at The University of Texas at Austin. Dr. Zhang's research interest is developing highperformance energy storage materials and systems.

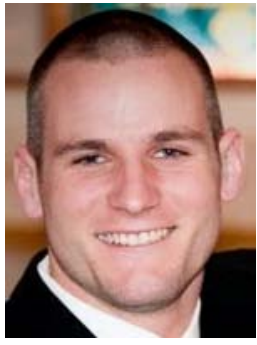

John McDonough received his BS in Physics in 2009 from Lycoming College. Presently, he is a Ph.D. candidate at Drexel University in the department of Materials Science and Engineering, studying under the guidance of Yury Gogotsi. His research focuses on carbon nanomaterials for electrical energy storage, specifically with onion-like carbon for electrochemical capacitors. John serves as the president of the MRS chapter at Drexel and is also highly involved in the local ECS and ASM chapters. 


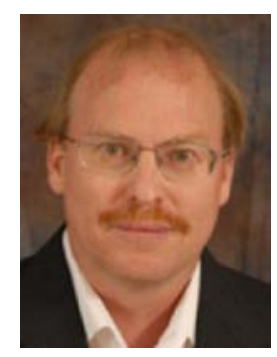

Rodney S. Ruoff joined The University of Texas at Austin as a Cockrell Family Regents endowed chair in September, 2007. His Ph.D. is in Chemical Physics from the University of Illinois-Urbana (1988) and he was a Fulbright Fellow in $1988-89$ at the Max Planck Institute fuer Stroemungsforschung in Germany. He was the John Evans Professor of Nanoengineering at Northwestern University and director of NU's Biologically Inspired Materials Institute from 2002-2007. He has co-authored 330 peer-reviewed publications devoted to materials science, chemistry, physics, mechanics, engineering, and biomedical science. He is a Fellow of the APS and the AAAS.

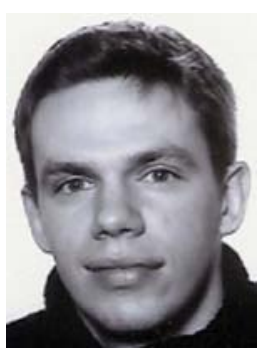

Pierre-Louis Taberna is a CNRS researcher at the CIRIMAT UMR 5085 - Université de Toulouse III, France. He has been working for more than ten years on the study and the modification of interfaces for energy storage materials. The aim of his work is mainly to nano-architect electrodes both for supercapacitors and lithium ion batteries. Along with performance enhancement it is aimed also to achieve a better understanding of charge storage mechanisms.

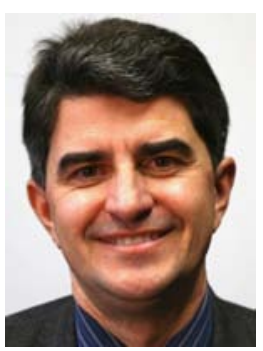

Dr. Yury Gogotsi is Distinguished University Professor and Trustee Chair of Materials Science and Engineering at Drexel University. He also serves as Director of the A.J. Drexel Nanotechnology Institute. His Ph.D. is in Physical Chemistry from Kiev Polytechnic and D.Sc. in Materials Engineering from the Ukrainian Academy of Sciences. His research group works on nanostructured carbons and other nanomaterials. He has co-authored more than 300 journal papers. He is a Fellow of AAAS, MRS, ECS and ACerS and a member of the World Academy of Ceramics.

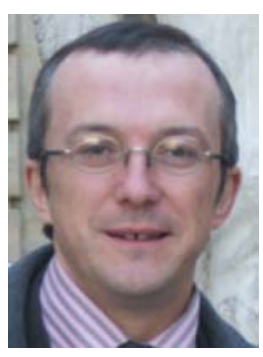

Patrice Simon obtained his PhD in 1995 in Material Science at Ecole NationaleSupérieure de Chimie de Toulouse. He joined the Conservatoire National des Arts et Métiers in Paris in 1996 as Assistant Professor and moved to Université Paul Sabatier in 2001, where he is currently Professor of Material Science. He holds a Chair of Excellence of the EADS Foundation and was awarded in 2011 with an Advanced Grant from the European Research Council (ERC, lonaces project). His research is focused on the synthesis and characterization of nanostructured materials for electrochemical capacitors and $\mathrm{Li}$-ion batteries. 